SINERGI 2021, Volume 19 (1): 80-87

DOI : $\underline{\text { http://dx.doi.org/10.31963/sinergi.v19i1.2762 }}$

\title{
Evaluasi Keandalan PLTA Bakaru
}

\author{
Akbar Tanjung ${ }^{1}$, Arman Jaya ${ }^{2}$, Suryanto ${ }^{3 *}$, Apollo ${ }^{4}$ \\ 1,2,3,4 Jurusan Teknik Mesin, Politeknik Negeri Ujung Pandang, Makassar 90245, Indonesia \\ *suryanto@poliupg.ac.id
}

\begin{abstract}
One form of water energy utilization is done by building a Hydroelectric Power Plant (PLTA) in Indonesia, the Bakaru PLTA is one of the projects within PT. PLN (Persero). This project is a Hydro Power Plant Master project with a SULSELRABAR transmission located $246 \mathrm{~km}$ from the city of Makassar. The operation of the Bakaru hydropower system is certainly expected to work optimally, reliably and efficiently. Therefore, evaluation or data on the performance of the generator itself is needed. This study was conducted to determine the condition of the Bakaru hydropower plant based on the equivalent availability factor (EAF) and Net Capacity Factor (NCF) and Cost of Production (BPP). The data used is operating data on the Bakaru hydropower plant for 1 year. The data was obtained by using the documentation technique, while the data analysis was carried out using the Microsoft Excel program. After conducting research, it can be concluded that the condition of the Bakaru hydropower plant in 2017 is considered normal, seen from the EAF value reaching $94.15 \%$ and the average EFOR value of 2.4\% with the number of Service Hours (SH) of 16,912.93 hours from 2 units. with the percentage of Service Hours to Period Hours reaching 96.53\%. Meanwhile, the Net Capacity Factor of the Bakaru hydropower plant in 2017 reached $85.83 \%$, with a total gross energy production of $945,372.50 \mathrm{MWh}$. This value exceeds the target that has been set.
\end{abstract}

Keywords: PLTA Evaluation, EAF, NCF and BPP

\begin{abstract}
Abstrak: Salah satu bentuk energi terbarukan sederhana yang banyak digunakan adalah energi air (Hydro Power). Salah satu bentuk pemanfaatan energi air dilakukan dengan membangun Pembangkit Listrik Tenaga Air (PLTA) di Indonesia, PLTA Bakaru adalah salah satu proyek dilingkungan PT. PLN (Persero). Proyek ini adalah proyek Induk Pembangkit Hidro dengan transmisi SULSELRABAR berjarak $246 \mathrm{~km}$ dari kota Makassar. Pengoperasian sistem PLTA Bakaru tentunya diharapkan dapat bekerja secara optimal, handal, dan efisien. Oleh karena itu, dibutuhkan evaluasi ataupun data tentang kinerja pembangkit itu sendiri. Penelitian ini dilakukan untuk mengetahui bagaimana kondisis PLTA Bakaru berdasarkan nilai equivalent availability factor (EAF) dan Net Capacity Factor (NCF) serta Biaya Pokok Produksi (BPP). Data yang digunakan yaitu data operasi pada PLTA Bakaru selama 1 tahun. Data-data tersebut diperoleh dengan teknik dokumentasi, sedangkan analisis data dilakukan dengan dengan menggunakan program Microsoft Excel. Setelah melakukan penelitian maka dapat disimpulkan bahwa kondisi PLTA Bakaru di tahun 2017 dianggap normal dilihat dari nilai EAF mencapai 94,15\% dan rata-rata nilai EFOR sebesar 2,4\% dengan jumlah Service Hours (SH) sebesar 16.912,93 jam dari 2 unit yang ada dengan persentase nilai Service Hours terhadap Period Hours mencapai 96,53\%. Sementara itu nilai Net Capacity Factor PLTA Bakaru di tahun 2017 mencapai 85,83\%, dengan total Produksi energi bruto mencapai 945.372,50 MWh. Nilai tersebut melebihi target yang telah di tetapkan.
\end{abstract}

Kata kunci : Evaluasi PLTA, EAF, NCF dan BPP

\section{PENDAhuluan}

PLTA Bakaru adalah salah satu proyek dilingkungan PT. PLN (Persero). Proyek ini adalah proyek Induk Pembangkit Hidro dengan transmisi SULSELRABAR berjarak $246 \mathrm{~km}$ dari kota Makassar. Proyek ini dibangun untuk memenuhi kebutuhan listrik di kota Makassar serta kebutuhan industri-industri yang berkembang dan perusahaan-perusahaan besar lainnya yang berada dipantai barat Sulawesi Selatan. Proyek PLTA Bakaru dibangun untuk meningkatkan penyediaan produksi tenaga Non-BBM Sulawesi Selatan yaitu dengan memanfaatkan sumber daya air dari aliran sungai Mamasa [1].

Oleh karena itu, dibutuhkan evaluasi ataupun data tentang kinerja pembangkit itu sendiri. Penelitian ini bertujuan mengetahui kinerja pembangki berdasarkan nilai Equivalent Availability Factor (EAF) dan Net Capacity Factor (NCF). Namun, untuk mendapatkan nilai dari kedua faktor tersebut (EAF dan 
NCF) dibutuhkan beberapa indikator pendukung seperti Plant Hours/jumlah jam beroperasi, Outage/unit tak beroperasi, Derating/penurunan performa unit dll. Kinerja pembangkit dihitung berdasarkan DKP-IKP 2007:1 tentang Prosedur Tetap Deklarasi Kondisi Pembangkit dan Indeks Kinerja Pembangkit [2].

Evaluasi pengusahaan pembangkit mencakup keandalan kinerja suatu pembangkit. Keandalan tenaga listrik didefinisikan sebagai peluang dari suatu peralatan untuk beroperasi sesuai dengan fungsinya dalam suatu selang waktu tertentu dan dalam kondisi operasi tertentu pula, sehingga dapat memenuhi kebutuhan listrik konsumen [3]. Untuk melakukan evaluasi pengusahaan pembangkit, diperlukan analisis yang rasional dan ilmiah. Adapun hal-hal yang perlu diulas adalah sebagai berikut:

\section{A. Equivalent Availability Factor (EAF)}

Tingkat Kesiapan Pembangkit atau Equivalet Availability Factor yang sering disingkat EAF pengertiannya dalam pembangkit listrik adalah faktor yang menunjukkan persentase kesiapan pembangkit dalam kurun waktu tertentu (biasanya 1 tahun), dan secara matematis adalah rasio antara jumlah jam pembangkit siap terhadap total jam dalam satu tahun dan telah memperhitukan dampak dari derating pembangkit [4].

Berikut merupakan persamaan untuk menentukan EAF:

$E A F=\left[\frac{S H-P O-P D}{P H}\right] X 100 \%$

Keterangan:

$\mathrm{SH}=$ Service Hours (Jumlah Jam Operasi)

$\mathrm{PH}=$ Plant Hours (Jumlah Jam dalam suatu periode)

$\mathrm{PO}=$ Plant Outage (Jumlah Jam Tak Beroperasi)

$\mathrm{PD}=$ Plant Derating (Jumlah jam penurunan performa)

\section{B. Produksi Energi}

Merupakan perekaman atau pencatatan energi yang mampu dihasilkan tiap unit pembangkit baik itu harian, mingguan, bulanan, hingga tahunan. Nilai dari produksi energi mempunyai peran penting dalam menentukan kinerja unit pembangkit, semakin tinggi produktivitas energi tiap unit semakin baik pula kinerja unit tersebut [5].

\section{Biaya Pokok Produksi (BPP)}

Biaya Pokok Produksi merupakan hasil akhir dari penentuan harga suatu produk yang dihasilkan suatu perusahaan. Dalam [6] dinyatakan bahwa "Harga pokok produksi merupakan biayabiaya yang dapat diukur dengan satuan uang untuk mengolah bahan baku menjadi produk jadi siap untuk dijual, dimana biaya-biaya ini terdiri dari biaya bahan baku, biaya tenaga kerja langsung, dan biaya overhead pabrik." Dalam menentukan BPP PLTA Bakaru 2017, ada beberapa indikator yang menjadi faktor penentu BPP yaitu;
a) BBM dan Pelumas
b) Pemeliharaan - jasa borongan
c) Pemeliharaan - material
d) Kepegawaian
e) Administrasi dan Umum
f) Depresiasi 
Dari ke enam indikator diatas yang kemudian di totalkan dan dibagi dengan jumlah energi yang dihasilkan untuk menentukan nilai BPP tiap bulannya. Untuk lebih jelasnya dapat dilihat pada rumus berikut ini:

$$
B P P=\frac{\text { Total biaya }}{\text { Total Produksi Energi }}
$$

\section{Net Capacity Factor (NCF) dan Capacity Factor (CF)}

Capacity factor adalah rasio energi yang sebenarnya diproduksi dibagi dengan total energi yang akan dihasilkan jika pembangkit dioperasikan sepanjang waktu, dengan tidak perlu untuk pemeliharaan pembangkit atau pengurangan keluaran (karena aliran air rendah atau kekeringan [7]. Sedangkan pendapat lain mengungkapkan bahwa, Capacity factor didefinisikan sebagai energi yang dihasilkan oleh pembangkit selama 1 tahun, dibagi dengan jumlah total energi yang dihasilkan pada rating daya yang telah dioperasikan terus menerus sepanjang tahun [8].

Untuk lebih jelasnya dapat dilihat pada rumus berikut ini:

$$
\begin{aligned}
& \text { NCF }=\frac{\sum[\text { Produksi Netto }]}{\Gamma \cdot[\text { DMN } x \text { PH }]} \times 100 \% \\
& C F=\frac{\sum[\text { Produksi Bruto }]}{\sum[\text { DMN } x \text { PH }]} \times 100 \%
\end{aligned}
$$

keterangan:

a. Produksi Bruto

Merupakan total produksi energi listrik dalam satuan $\mathrm{kWh}$ atau MWh.

b. Produksi Netto

Merupakan produksi energi listrik dalam satuan $\mathrm{kWh}$ atau MWh yang disalurkan ke Sistem Penyaluran dengan perhitungan Produksi bruto dikurangi energi Peamakaian Sendiri (PS).

c. PH (Period Hours)

Merupakan jumlah jam tersedia dalam suatu periode tertentu yang sedang diamati selama unit dalam status aktif.

d. Daya Mampu Netto

Merupakan kapasitas maksimum unit pembangkit yang beroperasi terus menerus dalam keadaan stabil dan aman setelah dikurangi kapasitas pemakaian sendiri.

\section{METODE PENELITIAN}

Data yang diperoleh akan dievaluasi sesuai dengan tujuan penelitian ini dengan melakukan perhitungan indikator kinerja unit pembangkit Bakaru yakni EAF (Equivalent Availability Factor), dan NCF (Net Capacity Factor) dimulai dari bulan Januari tahun 2017 sampai dengan bulan Desember tahun 2017. Perhitungan yang digunakan berdasarkan pada DKP-IKP 2007:1 tentang Prosedur Tetap Deklarasi Kondisi Pembangkit dan Indeks Kinerja Pembangkit PT. PLN (Persero). Nilai indikator kinerja pembangkit yang diperoleh selama satu tahun disajikan dalam bentuk tabel dan menarik kesimpulan. Pengambilan data berdasarkan database pengusahaan bulan Januari tahun 2017 sampai dengan bulan Desember tahun 2017 pada PT. PLN (Persero) Wilayah Sulselrabar Pembangkitan Bakaru 2 x 63 MW. 


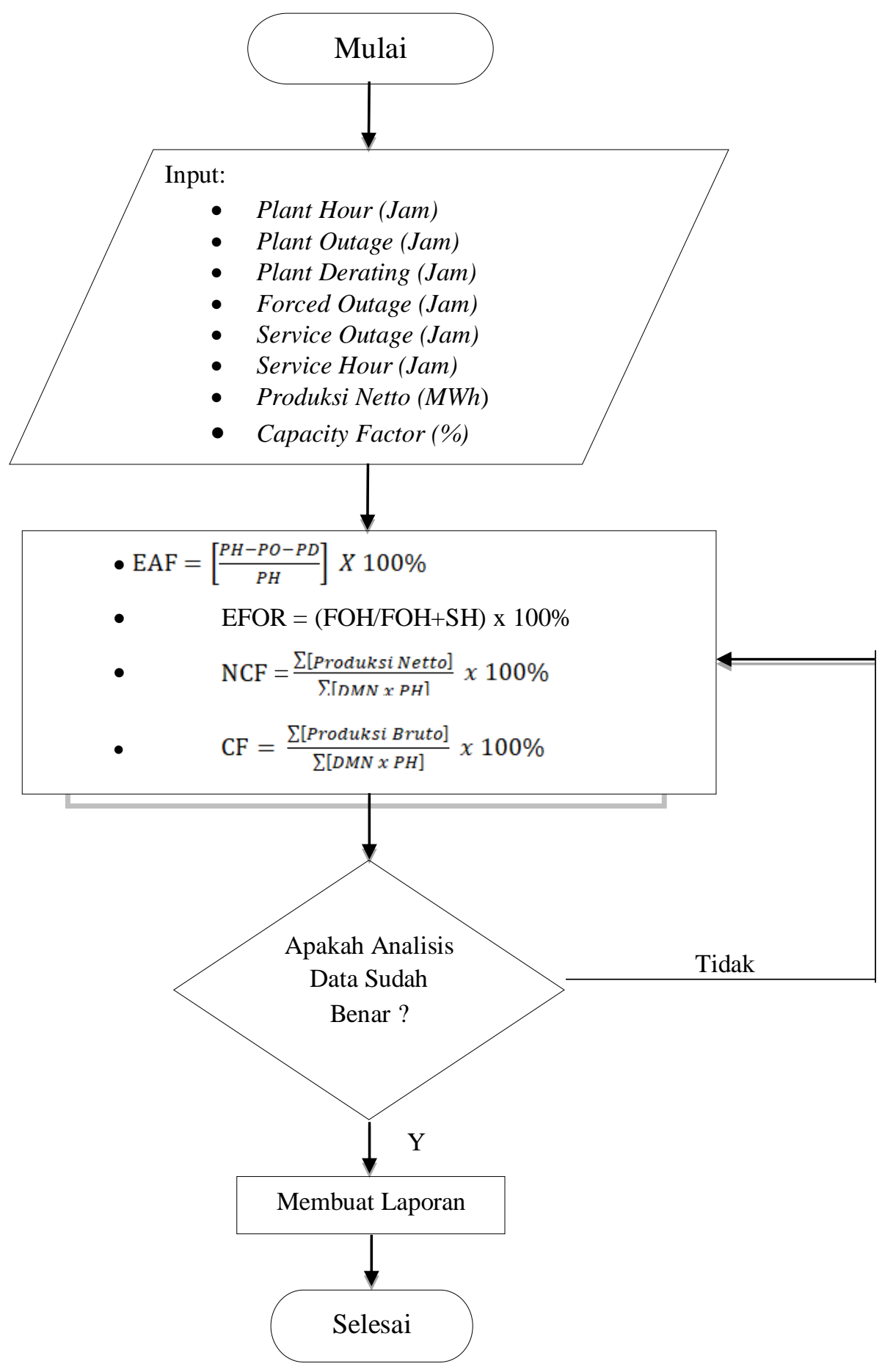

Gambar 1. Bagan alir penelitian 


\section{HASIL DAN PEMBAHASAN}

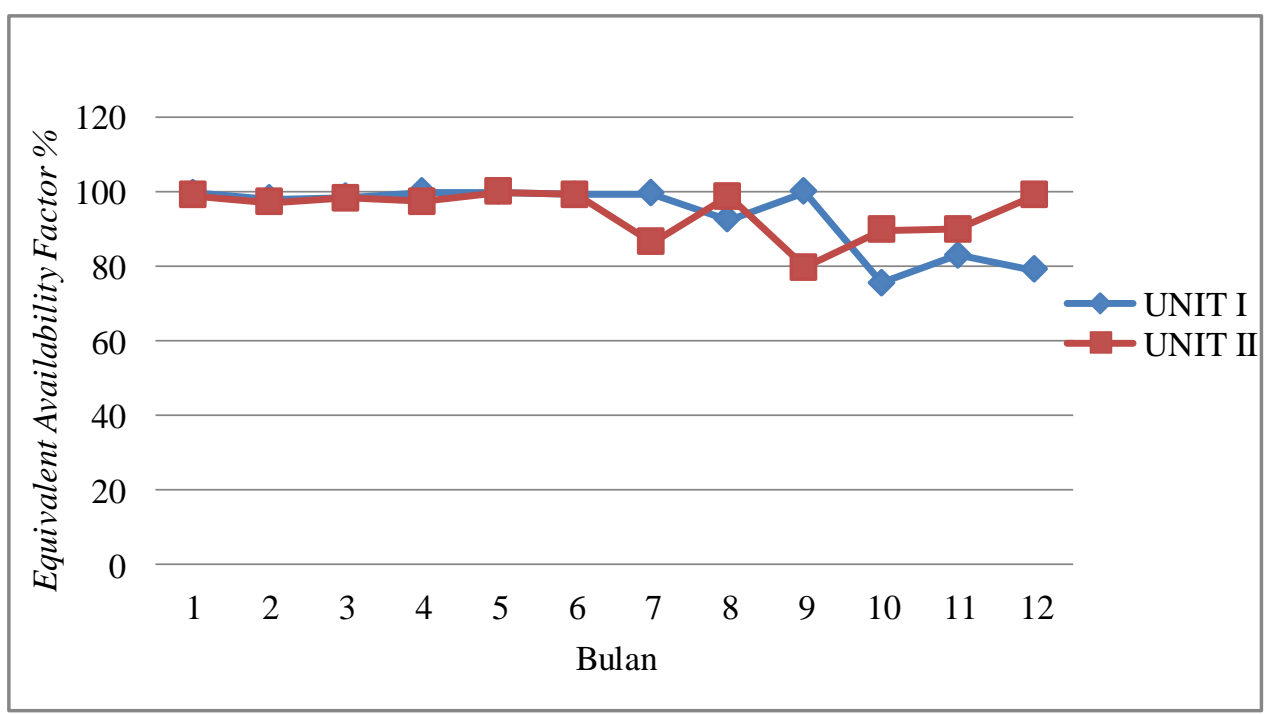

Gambar 2. Grafik EAF Unit I \& II terhadap waktu

Dari Gambar 2 diatas dapat dilihat bahwa Equivalent Availability Factor Unit I dari Januari hingga Juli cenderung konstan dan dalam kondisi handal dalam melakukan pengusahaan pembangkit. Kemudian dibulan Agustus hingga Desember nilai EAF Unit I mulai mengalami fluktuasi yang cukup signifikan. Fluktuasi nilai EAF pada Unit I sebagian besar disebabkan oleh banyaknya Outage. Jika membandingkan kedua unit yang ada, dimana kita ketahui kedua unit tersebut memiliki DMN yang sama yakni 63 MW maka dapat dikatakan Unit II lebih unggul dibandingkan Unit I. Meskipun Unit I lebih unggul di Service Hours (SH), namun Unit II unggul dalam nilai minimum Plant Outage (PO). Nilai PO Unit II hanya 94,83 jam dibandingkan dengan Unit I dengan Nilai PO mencapai 244,36 jam, hal inilah yang menyebabkan rata-rata EAF Unit II lebih tinggi dibandingkan Unit I.

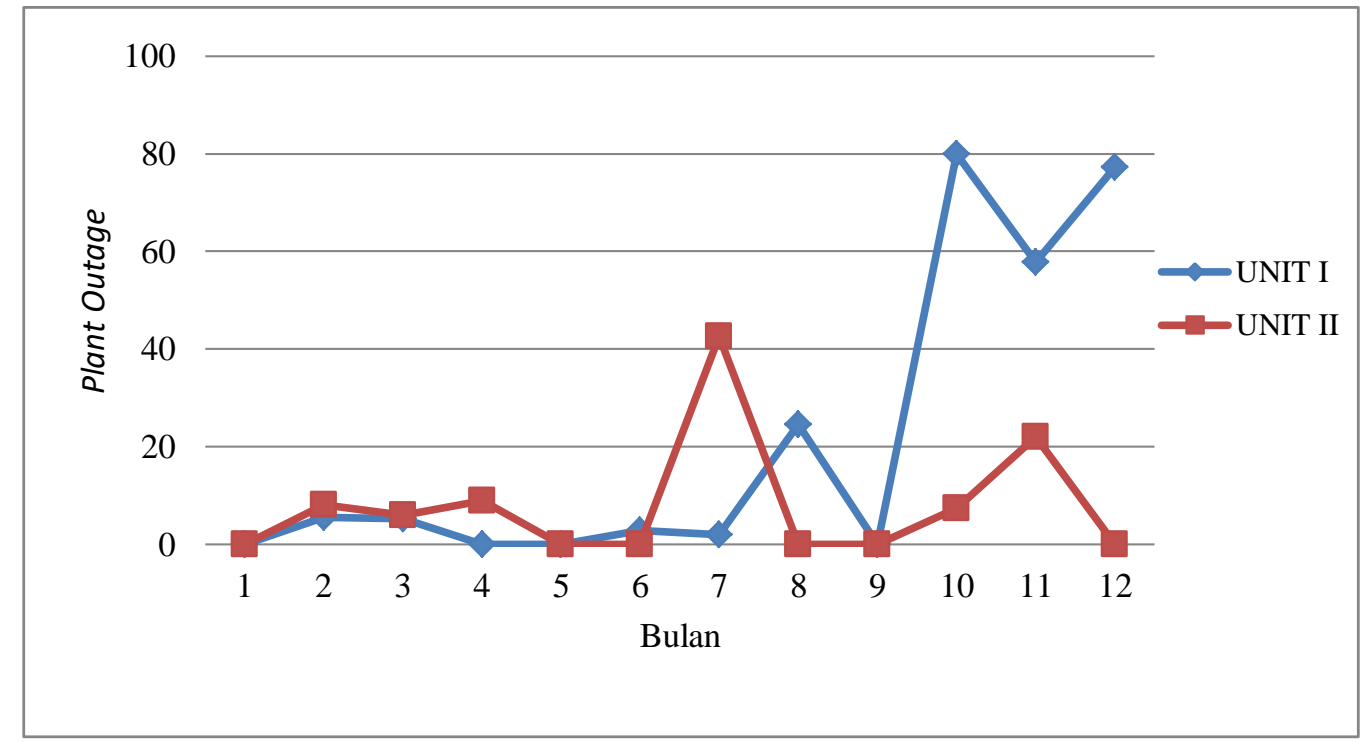

Gambar 3. Grafik Plant Outage (PO) Unit I \& II terhadapa waktu 


\section{A. Produksi Energi}

Total produksi bruto tahun 2017 sebesar 945.372,50 MWh, jauh melebihi targetnya sebesar 700.055,51 MWh atau selisih 35,04\% dari target yang ada.. Hal ini disebabkan oleh nilai service factor yang tidak maksimal karena faktor-faktor seperti Outage, Standby, Maintenance dan Derating serta suplai air yang tidak konstan seperti yang telah dijelaskan sebelumnya.

Sedangkan total energi yang dapakai pembangkit (Pemakaian Sendiri) mencapai total $1.808,72 \mathrm{MWh}$, nilai tersebut melebihi target pemakaian sendiri yang telah ditetapkan sebesar 1.636,15 MWh. Untuk bulan-bulan berikutnya di tahun 2017 dapat dilihat pada Gambar 7.

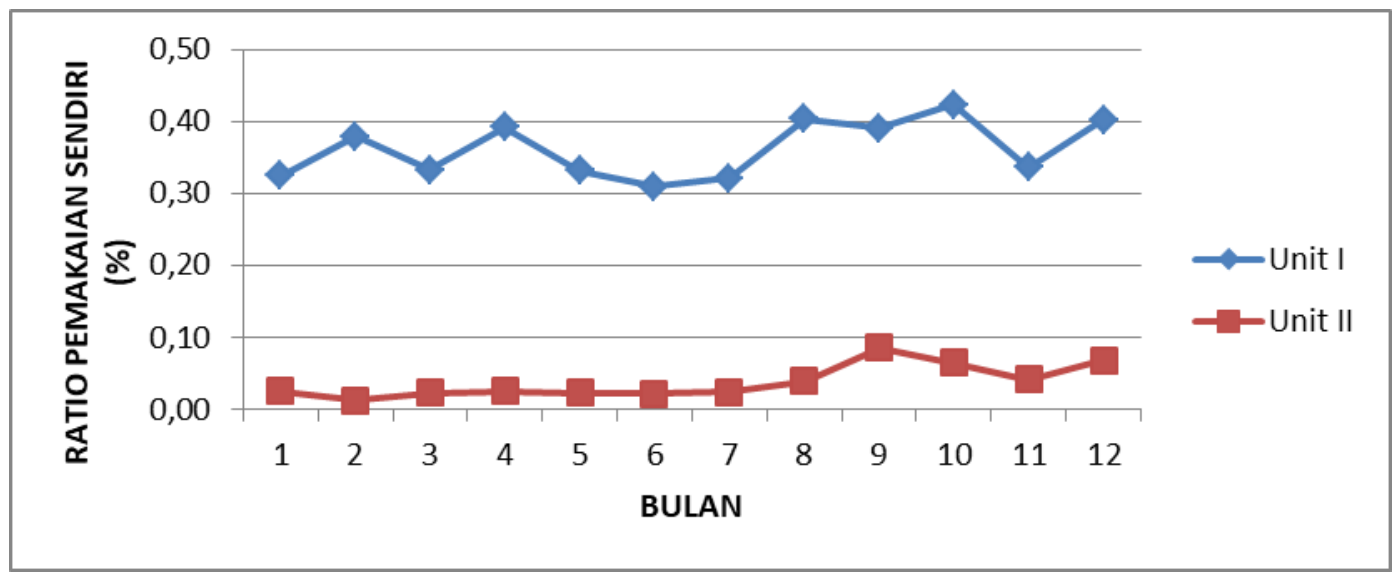

Gambar 4. Grafik Pemakaian Sendiri tehadap Energi yang dibangkitkan

Dari gambar 4. terlihat penggunaan / konsumsi energi Unit I \& II yang begitu berbeda, hal ini karena komponen-komponen pendukung pembangkitan dibebankan kepada Unit I sedangkan Unit II hanya melakukan distribusi energi di bagian penerangan. Jadi wajar saja jika konsumsi energi Pemakaian Sendiri di Unit I lebih besar dibandingkan dengan Unit II.

\section{B. Biaya Pokok Produksi}

Tabel 1. Biaya Pokok Produksi Tahun 2017 PLTA Bakaru

\begin{tabular}{|l|c|c|c|}
\hline \multicolumn{1}{|c|}{ Bulan } & $\begin{array}{c}\text { Energi Yang } \\
\text { Dibangkitkan } \\
(\mathbf{k W h})\end{array}$ & $\begin{array}{c}\text { Total Biaya } \\
\mathbf{( R p )}\end{array}$ & $\begin{array}{c}\text { Biaya Pokok Produksi } \\
(\mathbf{R p} / \mathbf{k W h})\end{array}$ \\
\hline Januari & $86.101 .300,00$ & $7.303 .353 .483,48$ & 84,82 \\
\hline Februari & $71.057 .800,00$ & $7.510 .548 .891,67$ & 105,70 \\
\hline Maret & $88.417 .900,00$ & $9.989 .212 .242,50$ & 112,98 \\
\hline April & $73.052 .300,00$ & $8.195 .222 .389,85$ & 112,18 \\
\hline Mei & $91.979 .200,00$ & $10.239 .324 .392,83$ & 111,32 \\
\hline Juni & $89.911 .000,00$ & $9.714 .085 .826,73$ & 108,04 \\
\hline Juli & $87.192 .100,00$ & $9.317 .321 .691,34$ & 106,86 \\
\hline Agustus & $80.289 .600,00$ & $8.690 .022 .057,64$ & 108,23 \\
\hline September & $56.648 .800,00$ & $6.291 .897 .937,48$ & 111,07 \\
\hline Oktober & $63.839 .200,00$ & $7.322 .976 .867,13$ & 114,71 \\
\hline November & $80.668 .300,00$ & $9.331 .513 .187,03$ & 115,68 \\
\hline Desember & $76.215 .000,00$ & $9.059 .514 .973,52$ & 118,87 \\
\hline \multicolumn{1}{|c|}{ TOTAL } & $945.372 .500,00$ & $102.964 .993 .941,19$ & 108,91 \\
\hline
\end{tabular}


Tabel 1. merupakan bentuk sederhana yang memperlihatkan total biaya yang digunakan, total energi yang dibangkitkan, serta Biaya Pokok Produksi tiap bulannya yang berfluktuasi mengikuti perubahan produksi energi dan biaya. Dari total biaya dan total produksi energy sepanjang 2017, didapatkan BPP PLTA Bakaru 2017 adalah sebesar Rp.108,91/kWh. Maka dari nilai BPP tersebut, dan juga berdasarkan harga listrik nasional per 1 Mei 2017 sebesar Rp.1.352 maka diperkirakan total penghasilan atau laba bruto PLTA Bakaru di tahun 2017 sebesar 1,2 Triliun.

\section{Net Capacity Factor (NCF) dan Capacity Factor (CF)}

Nilai rata-rata Net Capacity Factor PLTA Bakaru adalah sebesar 85,83\% dengan nilai Capacity Factor sebesar 85,61\%. Sementara itu, Rambe (2014a:1) mengatakan bahwa "Dari sisi kualitas PLTU dipengaruhi oleh besarnya kapasitas faktor dan faktor ketersediaan terhadap produksi listrik. dalam penelitian ini didapat nilai kapasitas faktor sebsesar 70,52\%. Jika dibandingkan dengan nilai Capacity Fator PLTA Bakaru di tahun 2017 yang mencapai 85,61\%, angka tersebut membuktikan bahwa unit pembangkitan PLTA Bakaru dalam kondisi handal dalam memproduksi energi pada tahun 2017 dapat dilihat pada Gambar 5.

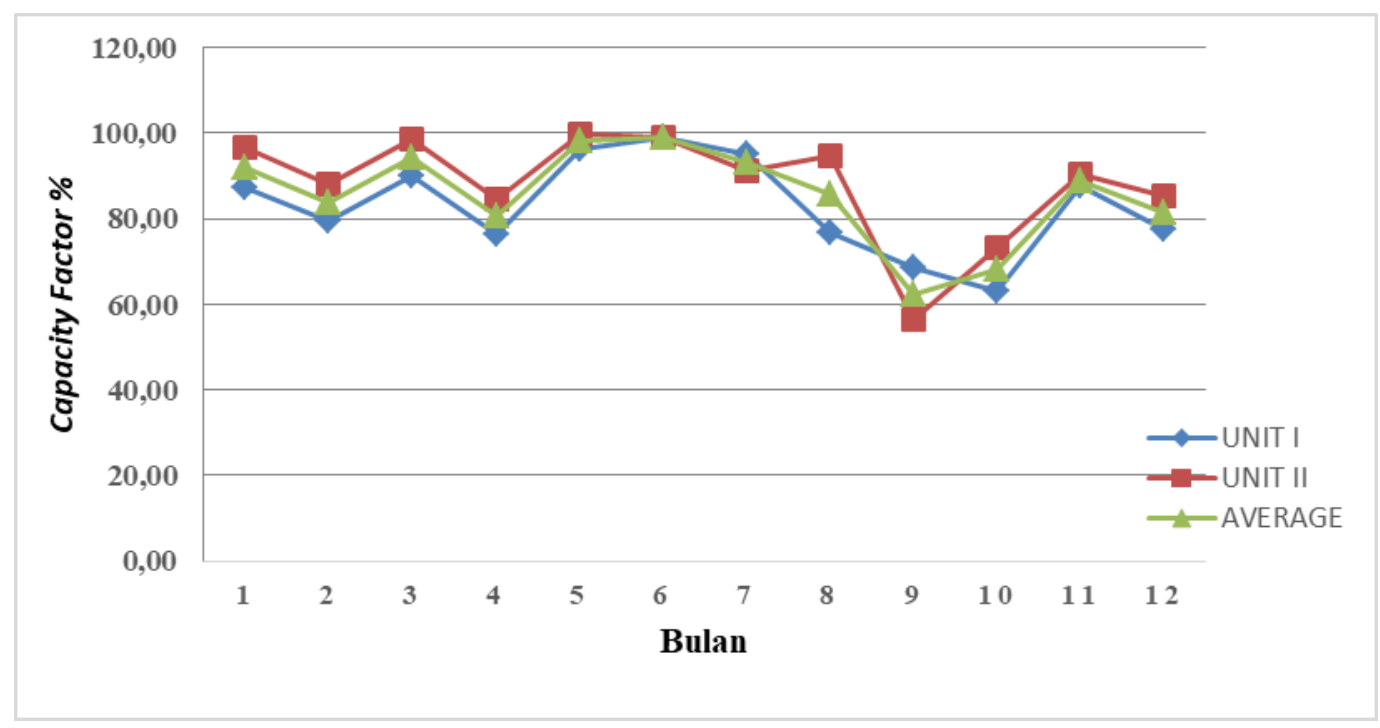

Gambar 5. Grafik Capacity Factor terhadap Waktu

\section{KESIMPULAN}

Berdasarkan dengan hasil dan pembahasan yang telah diuraikan diatas, maka dapat disimpulkan bahwa:

a. Kondisi PLTA Bakaru di tahun 2017 berdasarkan hasil anlisis nilai EAF menunjukkan hasil yang andal. Nilai EAF yang cukup tinggi membuktikan tingkat kesiapan unit dalam memproduksi energi.

b. Ditahun 2017 Net Capacity Factor PLTA Bakaru mencapai 85,83\%, pada PLTA secara umum nilai NCF PLTA Bakaru sudah tinggi, apalagi lifetime PLTA Bakaru terbilang sudah lama dan seharusnya mengalami penurunan performa.

c. Rasio Biaya Pokok Produksi (BPP) PLTA Bakaru di tahun 2017 terhadap Tarif Listrik di tahun 2017 terbilang tinggi, sehingga profit yang dihasilkan cukup memuaskan. 


\section{DAFTAR PUSTAKA}

[1] Adwianto, Muh Irsandi. 2017. Sistem Oli Bertekanan pada Unit PLTA Bakaru. Laporan Kerja Praktek. Makassar: Politeknik Negeri Ujung Pandang.

[2] Kelompok Bidang Umum Standarisasi dengan Surat Keputusan Direksi PT. PLN (Persero) No. 094.K/DIR/2006. 2007. Standar Indikator Kinerja Pembangkit. Jakarta Selatan: PT. PLN (Persero).

[3] Syahrial, Kania Sawitri, dan Partrianti Gemahapsari. 2017. Studi Keandalan Ketersediaan Daya Pembangkit Listrik pada Jaringan Daerah “X”. Dalam Jurnal Elkomika, Vol. 5 No. 1, Januari-Juni 2017:93-105.

[4] Haposan, Thommi. 2008. Perbaikan Tingkat Kesiapan Pembangkit pada PT. X dengan Metode Benchmarking. Tesis. Jakarta: Universitas Indonesia.

[5] PT. POSO ENERGY. 2015. Laporan Evaluasi Pengusahaan PLTA POSO 2. Penerbit: PT. POSO ENERGY.

[6] Ariskawati, Mila dan Sumanto. 2014. Perhitungan Harga Pokok Produksi dengan Metode Harga Pokok Pesanan. Dalam Jurnal Akuntansi Bisnis dan Perbankan Indonesia (JABPI) Vol. 22 No. 2 Juli 2014. Semarang.

[7] Prado, Fernando Almeida Jr dan Sanvord V, Berg. 2013. Capacity factors of Brazilian hydroelectric power plants: Implications for cost effectiveness. Public Utility Research Center University of Florida.

[8] Lester, Richard K. Dan Mark J. McCabe. 1993. The effect of industrial structure on learning by doing in nuclear power plant operation. Dalam Journal of Economics Vol. 24, No. 3, Australia. 